3 Davies M, Clements MR, Mawer EB, Freemont AJ Tumoral calcinosis: clinical and metabolic response to Tumoral calcinosis: clinical and metabolic response

4 Salvi A, Cerdulli B, Cimino A, Zuccato F, Giustina G. Phosphaturic action of calcitonin in pseudotumoral calcinosis (letter). Horm Metab Res 1983;15:260.
5 Lyles KW, Burkes EJ, Ellis GJ, et al. Genetic transmission of tumoral calcinosis: autosomal dominant with variable clinical expressivity. F Clin Endocrinol Metab 1985;60:1093-6.

6 Kindbolm LG, Gunterberg B. Tumoral calcinosis: an ultrastructural analysis and consideration of pathogenesis. APMIS 1988;96:368-76.

\title{
Fever of unknown origin
}

\author{
S Anuradha, N P Singh, S K Agarwal, N C Krishnamani
}

A 68-year-old man presented with a history of low-grade, continuous fever and malaise for 3 years. There was no associated history of cough, breathlessness, palpitations, headache, vomiting, joint pains, rash, urinary or bowel disturbances. The patient had been investigated on many occasions in the past for the fever. The investigations, including haemoglobin, blood counts, peripheral smear examination, kidney and liver functions tests, chest X-ray and ultrasonography of the abdomen, were all normal. The only abnormality detected was a persistently elevated erythrocyte sedimentation rate (ESR) of between 65 and $130 \mathrm{~mm}$ in the first hour. The patient had received several courses of antibiotics and was currently receiving antitubercular drugs prescribed empirically by a practitioner.

Examination revealed a conscious, febrile male with pulse 100 beats/min regular, and blood pressure $130 / 70 \mathrm{mmHg}$. The respiratory, cardiovascular, abdominal and neurological examination was unremarkable. The laboratory investigations of the patient are summarised in the table. A magnetic resonance imaging (MRI) scan of the thorax is shown in the figure.

Table Laboratory investigations

\begin{tabular}{lc}
\hline Investigations & Observed value (normal range) \\
\hline Haemoglobin $(\mathrm{g} / \mathrm{l})$ & $110(120-140)$ \\
Total leucocyte count $\left(\times 10^{9} / \mathrm{l}\right)$ & 8.4 \\
ESR $(\mathrm{mm}$ 1st hour) & $66(0-20)$ \\
Fasting blood sugar $(\mathrm{mmol} / \mathrm{l})$ & $5.0(4.2-6.4)$ \\
Blood urea nitrogen $(\mathrm{mmol} / \mathrm{l})$ & $5.3(3.6-7.1)$ \\
Serum creatinine $(\mu \mathrm{mol} / \mathrm{l})$ & $100(<133)$ \\
Alanine transaminase $(\mathrm{IU} / \mathrm{l})$ & $24(0-30)$ \\
Aspartate transaminase $(\mathrm{IU} / \mathrm{l})$ & $23(0-30)$ \\
Alkaline phosphatase $(\mathrm{IU} / \mathrm{l})$ & $100(<200)$ \\
Total proteins $(\mathrm{g} / \mathrm{l})$ & $70(60-80)$ \\
Serum protein electrophoresis & increase in the gamma \\
\multicolumn{2}{c}{ globulin fraction } \\
ANA, RA, VDRL and Elisa for HIV 1 and 2 were all negative \\
Urine examination, chest X-ray, ECG, and ultrasound \\
abdomen were all normal
\end{tabular}

Department of

Azad Medical College, and Associated Lok

Nayak Hospital, New

Delhi - 110 002, India

S Anuradha

N P Singh

S K Agarwal

N C Krishnamani

Correspondence to Dr S Anuradha, 3B/4, First Floor, Gangaram Hospital Road, New Delhi - 110 060, India

Accepted 14 January 1999

\section{Questions}

1 What is your provisional diagnosis?

2 How would you investigate the patient further?

3 Describe the MRI findings.

4 What is your final diagnosis?

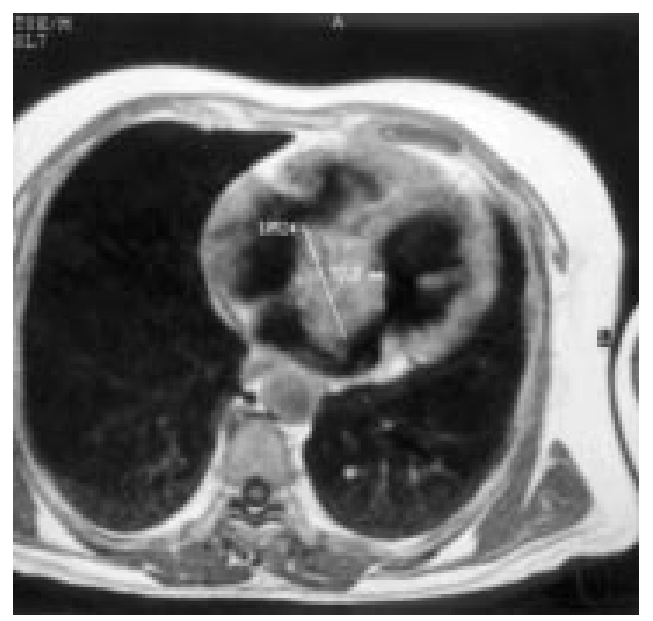

Figure MRI of the thorax 


\section{Answers}

QUESTION 1

Fever of unknown origin (FUO). By definition, ${ }^{1}$ FUO consists of:

- fever higher than $38.3^{\circ} \mathrm{C}\left(101^{\circ} \mathrm{F}\right)$ on several occasions

- a duration of more than three weeks, and

- failure to reach a diagnosis after 1 week of in-patient investigations.

FUO is one of the most frequently encountered clinical situations. Keen observation, patience and a diligent diagnostic work-up are mandatory for evaluating the cause of FUO. The major causes of FUO are listed in box 1. Of these, infections are still the leading cause, followed by neoplasms. With increasing duration of fever, the likelihood of an infectious aetiology diminishes and the other causes become more important.

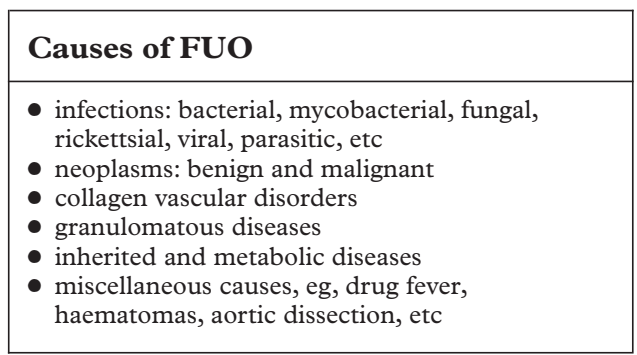

Box 1

QUESTION 2

Since the initial evaluation for the cause of fever was non-contributory, the further diagnostic work-up should include bone marrow aspiration/biopsy, liver biopsy, echocardiography and computed tomography or MRI of the chest and abdomen. Most causes of FUO can be detected after this screening. In our patient, the bone marrow aspiration revealed a normoblastic marrow with a myeloid to erythroid ratio $2: 1$. There was an increase in the plasma cells to $10-15 \%$ and megakaryopoiesis was normal.

QUESTION 3

The MRI scan of the thorax reveals a $5.2 \times 3.6$ $\mathrm{cm}$ mass arising from the interatrial septum on the left side in the region of the fossa ovalis and extending to the left ventricle, suggestive of a left atrial mass (? myxoma)

QUESTION 4

The patient successfully underwent tumour excision by a biatrial approach under cardiopulmonary bypass and histopathology confirmed the diagnosis of an atrial myxoma.

\section{Discussion}

Primary cardiac tumours are rare and are observed in $0.0017 \%$ to $0.28 \%$ of all autopsies. ${ }^{2}$ Atrial myxomas constitute $50-90 \%$ of these $e^{34}$ and $75 \%$ of the atrial myxomas have a left atrial origin. The tumours are considered to be benign by most, and recent evidence suggests that they may originate from the endocardial sensory nerve tissue. ${ }^{5}$

Atrial myxomas remain asymptomatic for varying periods before they manifest with classic features (box 2). Most tumours present with dyspnoea, chest pain, and fatigue; a third heart sound, tumour plop and a diastolic murmur are prominent auscultatory findings. ${ }^{4}$ Constitutional symptoms occur frequently, although it is rare for a cardiac myxoma to present as FUO alone, without any symptoms or signs referable to the cardiovascular system, as in this case. In two large series of 366 patients with FUO, an atrial myxoma was detected in only two patients. ${ }^{67}$ Many associated conditions coexist with atrial myxomas, especially with the familial types (box 3$){ }^{8}$

\section{Atrial myxomas: clinical presentations}

obstructive: features of mitral valvular obstruction simulating mitral stenosis

- embolic to: cerebrovascular circulation leading to neurologic syndromes; coronary vessels leading to myocardial infarction; other rare sites, eg, peripheral circulation

- constitutional symptoms: fever, weight loss, anorexia, arthralgias, anaemia; raised ESR, leucocytosis

- combinations of the above

Box 2

\section{Associations of familial atrial myxomas}

- skin manifestations: naevi, lentigenes, cutaneous myxomas

- myxoid mammary fibrodenomas

- hyperadrenalism and Cushing's syndrome

- haemolytic anaemia

- testicular (Sertoli cell) tumours

- thrombocytopenia

- acromegaly

Box 3

\section{Learning points}

- atrial myxomas may rarely present as isolated FUO

- all patients with FUO of a long duration should be screened by echocardiography for an underlying atrial myxoma

\section{Box 4}

Anaemia, leucocytosis and a raised ESR are usual, and cardiomegaly may be evident on a chest X-ray in some patients. Echocardiography is mandatory for the diagnosis of atrial myxomas and the transoesophageal route is superior to the transthoracic route 
in the identification of atrial masses. ${ }^{9}$ Recently, MRI has been shown to delineate the nature and extent of cardiac myxomas very well. ${ }^{10}$

Surgical excision is advisable for all atrial myxomas, even asymptomatic ones, as embolisation may have drastic results, and can even lead to sudden cardiac death. Recurrence of atrial myxomas after an initial excision is well known and is thought to represent an

1 Petesdorf RG, Beeson PB. Fever of unexplained origin Medicine 1961;40:1-30

2 Straus R, Merliss R. Primary tumours of the heart. Arch Pathol 1945;39:74-80.

3 Panos A, Kalagos A, Sztajzel J. Left atrial myxoma presenting with myocardial infarction. Case report and review of the literature. Int $\mathcal{F}$ Cardiol 1997;62:73-5.

4 Kar AK, Roy S, Chatterjee A, Banerjee A, Panja M, Mitra S. Cardiac tumours: an observational study. Indian Heart $\mathscr{f}$ 1996;48:257-60

5 Krikler DM, Rode J, Davies MJ, Wolf N, Moss E. Atrial myxoma: a tumour in search of its origins. Br Heart f 1992; 67:89-91.

6 Knockaert DC, Vanneste LJ, Vanneste SB, Bobbaers HJ Fever of unknown origin in the 1980s. An update of the diagnostic spectum. Arch Intern Med 1992;152:51-5. incomplete resection. The present case was unusual in that the atrial myxoma produced nosymptoms and signs other than a prolonged fever.

\section{Final diagnosis}

Left atrial myxoma.

Keywords: atrial mass; myxoma; fever of unknown origin

\footnotetext{
7 de Kleijn EMHA, Vandenbroucke JP, van den Meer JWM and the Netherlands FUO study group. Fever of unknown origin (FUO): I. A prospective multicenter study of 167 patients with FUO using fixed epidemiologic entry criteria Medicine 1997;76:392-401.

8 Van Gelder, O'Brien DJ, Staples ED, Alexander JA. Familial cardiac myxoma. Ann Thorac Surg 1992;53:419-24.

9 Alam M, Rosman HS, Grullon C. Transesophageal echocardiography in evaluation of atrial masses. Angiology 1995;46:123-8.

10 Matsuoka H, Hamada M, Honda T, et al. Morphologic and histologic characterisation of cardiac myxomas by magnetic resonance imaging. Angiology 1996;47:693-8.
}

\title{
A young woman with fever of unknown origin
}

\author{
A S Kashyap, Isaac Mathew, Shekhar Kashyap
}

A 33-year-old woman presented with a 2-month history of moderate-grade fever associated with chills, headache and diminished appetite. She had lost $8 \mathrm{~kg}$ since the onset of illness. Clinically, she had fever (temperature $38.5^{\circ} \mathrm{C}$ ), but the rest of the general physical and systemic examinations were normal.

Investigations revealed an erythrocyte sedimentation rate (ESR) of $80 \mathrm{~mm}$ after $1 \mathrm{~h}$. Routine haemogram, blood smear for malarial parasite, urine microscopic examination, urine culture, blood culture, chest X-ray and ultrasounds of abdomen and pelvis were noncontributory. Mantoux test was negative. She was initially treated empirically for malaria with chloroquine and subsequently with ciprofloxacin for enteric fever with no response. On repeated clinical examinations she was detected to have small, diffuse, nontender thyromegaly. A 131-radioiodine scan revealed markedly low uptake of tracer. Radioactive iodine uptake (RAIU) was negligible at $24 \mathrm{~h}$. Serum

Armed Forces Medical College, Pune 411 040, India

A S Kashyap

I Mathew

S Kashyap

Accepted 14 January 1999 tri-iodothyronine $\left(\mathrm{T}_{3}\right)$ was $180 \mathrm{ng} / \mathrm{dl}$ (normal 60-181), serum thyroxine $\left(\mathrm{T}_{4}\right) 10 \mu \mathrm{g} / \mathrm{dl}$ (normal 4.5-10.9) and thyroid-stimulating hormone (TSH) $0.4 \mu \mathrm{U} / \mathrm{ml}$ (normal 0.5-5.0).

\section{Questions}

1 What is the diagnosis?

2 Name two characteristic laboratory findings of this condition? 